\title{
Emergent Colorectal Surgery: What Should Be Considered?
}

\author{
Chang-Nam Kim \\ Department of Surgery, Eulji University School of Medicine, Daejeon, Korea
}

\section{See Article on Page 133-138}

In emergent settings for the treatment of colorectal diseases, diverse complications, including obstruction, perforation, ischemia, and sepsis, contribute to the high risk of both mortality and morbidity in comparison to scheduled settings. According to Western studies, the mortality and the complication rates are high in such cases, ranging from $10 \%$ to $25 \%$ and $30 \%$ to $50 \%$, respectively [13]. However, studies in Asia on colorectal surgery in such context are lacking despite the fact that a multitude of surgical treatments exist for the complications encountered under emergent colorectal conditions [4-7]. Due to the aging of, and the Westernization of dietary habits in, the Korean population, the incidences of malignant disorders such as colorectal cancer have been increasing alongside benign colorectal diseases such as diverticulitis and ischemic colitis. Despite the advances in colonoscopy and abdominal computed tomography imaging, which allow early diagnosis and intervention, colon cancer still poses a conundrum when delayed treatment causes complications such as intestinal obstructions or perforations. Diverticulitis, together with ischemic colitis, has seen improvements in medical treatment because of the development of antibiotics, but remains difficult to manage in patients with extensive abdominal contamination and sepsis [8-12]. Thus, more studies are needed to identify possible risk factors and complications in an emergent setting. Taking this into consideration, the authors [13], despite the small study group, have identified risk factors that influence the outcomes of emergent colorectal surgeries.

In emergency settings, two main points need close observation, the first being the factors involving the patient and the second being surgical factors. As to the former, aged patients and those with underlying diseases such as diabetes or chronic kidney disease

Correspondence to: Chang-Nam Kim, M.D.

Department of Surgery, Eulji University Hospital, Eulji University School of

Medicine, 95 Dunsanseo-ro, Seo-gu, Daejeon 35233, Korea

Tel: +82-42-259-1335, Fax: +82-42-259-1335

E-mail: kimcn@eulji.ac.kr

(C) 2016 The Korean Society of Coloproctology

This is an open-access article distributed under the terms of the Creative Commons Attribution NonCommercial License (http://creativecommons.org/licenses/by-nc/4.0) which permits unrestricted noncommercial use, distribution, and reproduction in any medium, provided the original work is properly cited. tend to show lower postoperative success. Such factors also apply to surgical treatments in nonelective cases [13]. In the case of an emergent open colectomy in elderly, geriatric patients, especially those above the age of 80 , have higher risk of death, and as for diverticulitis, age acts as an independent risk factor for mortality after emergent surgery $[14,15]$. Therefore, prior to intervention, age must be taken into account as it directly correlates to the outcome for the patient. American Society of Anesthesiologists (ASA) scores also contribute to the patient's postoperative results, and higher ASA scores are associated with more adverse results. ASA scores are currently utilized as predictors of surgical outcome both pre- and postoperatively [16-18]. Post et al. [19] stated that hypotension showed a high correlation with postoperative leakage, but not very many studies exist on the subject. Oh and Kim [13] found that hypotension and symptoms related to the condition prior to surgery indicate worse outcome. Therefore, blood pressure management before intervention needs more attention because it is, to an extent, a controllable factor. More studies are needed to identify care for such patients.

As to the surgical factors, the choice of surgical method directly relates to the results for the patient. The choice between fecal diversion and intestinal anastomosis can influence the overall outcome. As stated above, high ASA scores and preoperative hypotension lead to worse outcomes in emergent patients undergoing colorectal surgery. Personally, such high risk patients benefit from limited and prompt surgical methods, making fecal diversion more preferable over intestinal anastomosis. Intestinal anastomosis always carries the risk of leakage, even in elective situations, and serious complications may arise in patients already in difficulty. Therefore, the selection of proper procedures according to the patient's current health status outweighs the preference of the surgeon.

As for the choice between open or laparoscopic surgery, recent studies support that, in emergent settings, the latter leads to better outcome. Harji et al. [20], in a systemic review of 22 prior studies, reported better short-term outcomes, which included shorter hospital stays and lower complication rates, for the latter. The review concluded that an emergency laparoscopic colorectal resection was superior to traditional open methods.

In a study of laparoscopic surgery for diverticular disease, handassisted laparoscopic surgery (HALS), considering the multitude of patients with advanced age (conventional laparoscopic surgery, 
46.2 years old; HALS, 67.3 years old), showed results comparable to conventional laparoscopic surgery [21]. Indications of HALS include high ASA scores $(\geq 3)$, old age ( $\geq 75$ years old), high body mass index $\left(\geq 28 \mathrm{~kg} / \mathrm{m}^{2}\right)$, intestinal obstruction, bowel perforation, and peritoneal fecal contamination. Also, when the laparoscopic view of the abdomen provided limited information on the patient's condition, use of the tactile senses greatly aided the surgeon in identifying organ structures and the overall state of the intestine. In the patients with ischemic colitis, such is the case, and HALS provides the surgeon with the ability to identify intact portions of the colon more easily. Moreover, in the event of fecal contamination of the peritoneum in patients with colorectal perforation, HALS provides a better outcome for the patient. A hand port is inserted through a $7-\mathrm{cm}$ incision in the abdominal wall, which allows the surgeon convenience in performing irrigation and protecting against secondary infections of the surgical site. The hand port acts as a barrier for the opening of the surgical site, greatly decreasing the risk of contamination.

Multiple factors play a role in the overall mortality in emergent colorectal surgeries, and the patient's condition, along with the surgical setting, greatly influences the hospital course. Due to the paucity of studies on the subject and the lack of data in Eastern countries, recognizing the factors that impact the overall survival of the ill is crucial in an emergent clinical setting. In conclusion, a thorough understanding of the patient's current condition and an adequate surgical treatment is of utmost importance for improved survival of the patient.

\section{CONFLICT OF INTEREST}

No potential conflict of interest relevant to this article was reported.

\section{REFERENCES}

1. Isbister WH, Prasad J. Emergency large bowel surgery: a 15-year audit. Int J Colorectal Dis 1997;12:285-90.

2. Han EC, Ryoo SB, Park BK, Park JW, Lee SY, Oh HK, et al. Surgical outcomes and prognostic factors of emergency surgery for colonic perforation: would fecal contamination increase morbidity and mortality? Int J Colorectal Dis 2015;30:1495-504.

3. Aydin HN, Tekkis PP, Remzi FH, Constantinides V, Fazio VW. Evaluation of the risk of a nonrestorative resection for the treatment of diverticular disease: the Cleveland Clinic diverticular disease propensity score. Dis Colon Rectum 2006;49:629-39.

4. Kwan TL, Lai F, Lam CM, Yuen WC, Wai A, Siu YC, et al. Population-based information on emergency colorectal surgery and evaluation on effect of operative volume on mortality. World J Surg 2008;32:2077-82.

5. Choi KH, Hong YS, Suh SO, Moon HY. Colon perforation. J Korean Soc Coloproctol 1999;15:307-14.

6. Lee KU, Chung JK, Hong SK, Kim ST. Clinical study of colon ob- struction. J Korean Surg Soc 1982;24:192-9.

7. Kang DB, Shin CY, Lee JK, Park WC. Multivariate analysis of the risk factors associated with complications and mortality after and emergency operation for obstructive, perforated colorectal cancer. J Korean Soc Coloproctol 2009;25:165-71.

8. Tekkis PP, Poloniecki JD, Thompson MR, Stamatakis JD. Operative mortality in colorectal cancer: prospective national study. BMJ 2003;327:1196-201.

9. Tobaruela E, Camuñas J, Enríquez-Navascúes JM, Díez M, Ratia T, Martín A, et al. Medical factors in the morbidity and mortality associated with emergency colorectal cancer surgery. Rev Esp Enferm Dig 1997;89:13-22.

10. Edna TH, Jamal Talabani A, Lydersen S, Endreseth BH. Survival after acute colon diverticulitis treated in hospital. Int J Colorectal Dis 2014;29:1361-7.

11. Martel J, Raskin JB; NDSG. History, incidence, and epidemiology of diverticulosis. J Clin Gastroenterol 2008;42:1125-7.

12. Ryoo SB, Oh HK, Ha HK, Moon SH, Choe EK, Park KJ. The outcomes and prognostic factors of surgical treatment for ischemic colitis: what can we do for a better outcome? Hepatogastroenterology 2014;61:336-42.

13. Oh NH, Kim KJ. Outcomes and risk factors affecting mortality in patients who underwent colorectal emergency surgery. Ann Coloproctol 2016;32:133-8.

14. Kurian A, Suryadevara S, Ramaraju D, Gallagher S, Hofmann M, Kim S, et al. In-hospital and 6-month mortality rates after open elective vs open emergent colectomy in patients older than 80 years. Dis Colon Rectum 2011;54:467-71.

15. Lidsky ME, Thacker JK, Lagoo-Deenadayalan SA, Scarborough JE. Advanced age is an independent predictor for increased morbidity and mortality after emergent surgery for diverticulitis. Surgery 2012;152:465-72.

16. Prause G, Ratzenhofer-Comenda B, Pierer G, Smolle-Jüttner F, Glanzer H, Smolle J. Can ASA grade or Goldman's cardiac risk index predict peri-operative mortality? A study of 16,227 patients. Anaesthesia 1997;52:203-6.

17. Horiuchi A, Watanabe Y, Doi T, Sato K, Yukumi S, Yoshida M, et al. Evaluation of prognostic factors and scoring system in colonic perforation. World J Gastroenterol 2007;13:3228-31.

18. Wolters U, Wolf T, Stützer H, Schröder T. ASA classification and perioperative variables as predictors of postoperative outcome. $\mathrm{Br}$ J Anaesth 1996;77:217-22.

19. Post IL, Verheijen PM, Pronk A, Siccama I, Houweling PL. Intraoperative blood pressure changes as a risk factor for anastomotic leakage in colorectal surgery. Int J Colorectal Dis 2012;27:765-72.

20. Harji DP, Griffiths B, Burke D, Sagar PM. Systematic review of emergency laparoscopic colorectal resection. Br J Surg 2014;101: e126-33.

21. Jung JH, Kim CN, Park JS, Kim JY, Cho BS, Lee MK, et al. A comparison of standard laparoscopic surgery and hand-assisted laparoscopic surgery in patients with diverticular diseases of the large and the small bowel. J Korean Soc Coloproctol 2009;25:380-6. 